\title{
Editorial for the Special Edition on Tropical Cyclones in 2015-2016
}

The years 2015 and 2016 are characterized by tropical cyclones in the western North Pacific, with unique seasonality, unusual tracks, and record-breaking phenomena. The El Niño event strengthen throughout 2015 and no typhoons generate until early summer in 2016. In August 2016, a monsoon gyre has produced many named TCs in the western North Pacific and they involve Typhoon Lionrock (2016) that exhibited the unusual motion in a counterclockwise direction. Many typhoons such as Etau (2015) and Nepartak (2016) caused devastating hazards including strong winds, heavy rainfall and high waves. They are of meteorological and climatological interest, and have drawn a remarkable attention of the public, which have motivated the establishment of the Editorial Committee on the special issue of "Tropical cyclones in 20152016" on JMSJ. The Editorial Committee decided to accept eight papers for publication in the Special Edition as a collection online at http://jmsj.metsoc. jp/special_issues_editions/vol96no4.html

The papers in this Special Edition describe important contributions to researches of tropical cyclones and relevant atmospheric phenomena. Cao and $\mathrm{Wu}$ (2018) compared contributions of different environmental factors to tropical cyclone genesis over the western North Pacific during 2015 and 2016. Two papers focused on Typhoon Lionrock. Wada and Oyama (2018) revealed the role of convective bursts before Lionrock made landfall in northern Japan. Nayak and Takemi (2019) conducted pseudo global warming downscaling experiments of an extreme rain produced by Lionrock in order to assess the impacts of climate change on resulting hazards. Jin et al. (2019) evaluated the initial large-scale environment of the real-time forecast from the Coupled Ocean/Atmosphere Mesoscale Prediction System for Tropical Cyclone. The distributions of $500 \mathrm{hPa}$ height, upper-level divergence and 850-500 hPa moisture played important roles for intensification of Typhoon Nepartak. Using the nonhydrostatic icosahedral atmospheric model, Jinno et al. (2019) conducted a series of hindcast simulations to reproduce the temporal evolution of the monsoon gyre in August 2016, which yielded the genesis of multiple tropical cyclones. Two papers investigated extremely heavy precipitation affected by two typhoons that occurred around the Kinugawa River, Japan, in September 2015. Fujita et al. (2019) suggested the probability of extreme precipitation occurrence using data from large ensemble forecasts. Wada et al. (2019) investigated the influence of sea surface temperature on the local heavy rainfall event using a regional air-sea strongly coupled data assimilation system based on the local ensemble transform Kalman filter and a nonhydrostatic atmosphere model coupled with ocean-surface wave model and a multilayer ocean model. Fudeyasu and Yoshida (2019) examined the statistical characteristics of tropical cyclones for which the cyclogenesis process was modulated by upper tropospheric cold lows over the western North Pacific during the 38 years. The extremely hot summer of 2016 was partly enhanced by the intense Tibetan high, when 4 typhoons were defined as having cyclogenesis influenced by upper tropospheric cold lows. 
The Special Edition on Tropical cyclones in 2015-2016 provides a valuable opportunity for publishing papers to investigate the unique phenomena associated with tropical cyclones in 2015-2016, and is a vital addition to the body of work on tropical cyclones research. On behalf of the JMSJ Editorial Committee, we cordially thank the authors for their contributions and invite readers to make full use of this collection.

January 2019

Hironori Fudeyasu, Chief editor of the special issue Kosuke Ito: Associate chief editor of the special issue Masuo Nakano: Editorial manager of the special issue

\author{
Special Editorial Committee \\ Hironori Fudeyasu: Yokohama National University, \\ Chief editor of the special issue \\ Kosuke Ito: University of the Ryukyus, \\ Associate chief editor of the special issue \\ Masuo Nakano: Japan Agency for Marine-Earth Science and Technology, \\ Editorial manager of the special issue \\ Masaru Inatsu: Hokkaido University, Editor \\ Yoshiyuki Kajikawa: RIKEN Center for Computational Science, Editor \\ Sachie Kanada: Nagoya University, Editor of the special issue
}

\section{References}

Cao, X., and R. Wu, 2018: Comparison of different time scale contributions to tropical cyclone genesis over the western North Pacific in 2015 and 2016. J. Meteor. Soc. Japan, 96, 317-336.

Fudeyasu, H., and R. Yoshida, 2019: Statistical analysis of the relationship between upper tropospheric cold lows and tropical cyclone genesis over the western North Pacific. J. Meteor. Soc. Japan, 97, 439-451.

Fujita, M., T. Sato, T. J. Yamada, S. Kawazoe, M. Nakano, and K. Ito, 2019: Analyses of extreme precipitation associated with the Kinugawa River flood in September 2015 using a large ensemble downscaling experiment. J. Meteor. Soc. Japan, 97, 387-401.

Jin, H., Y. Jin, and J. Doyle, 2019: An evaluation of COAMPS-TC real-time forecasts for Super Typhoon Nepartak (2016). J. Meteor. Soc. Japan, 97, 191-203.

Jinno, T., T. Miyakawa, and M. Satoh, 2019: NICAM predictability of the monsoon gyre over the western North Pacific during August 2016. J. Meteor. Soc. Japan, 97, 533-540.

Nayak, S., and T. Takemi, 2019: Dynamical downscaling of Typhoon Lionrock (2016) for assessing the resulting hazards under global warming. J. Meteor. Soc. Japan, 97, 69-88.

Wada, A., and R. Oyama, 2018: Relation of convective bursts to changes in the intensity of Typhoon Lionrock (2016) during the decay phase simulated by an atmosphere-wave-ocean coupled model. J. Meteor. Soc. Japan, 96, 489-509.

Wada, A., H. Tsuguti, K. Okamoto, and N. Seino, 2019: Air-sea coupled data assimilation experiment for Typhoons Kilo, Etau and the September 2015 KantoTohoku heavy rainfall with the Advanced Microwave Scanning Radiometer 2 sea surface temperature. $J$. Meteor. Soc. Japan, 97, 553-575. 